\title{
Humanistic Inclusion: The Case for the Humanities in the Gulf
}

\author{
Dr. Christopher K. Brown
}

Zayed University, UAE

\begin{abstract}
One potential lesson to be learned from the academic "culture wars" of the past few decades, regardless of which position one prefers, is that the humanities as a discipline continue to matter, perhaps more so than ever in a multi-cultural, globalized world. The systematic marginalization, even elimination, of the humanistic disciplines available represents a significant weakness for education in the Gulf; bolstering the study of the humanities - including literature, philosophy, and art history - offers a proven route towards achieving certain goals publicly avowed as priorities for education in the region. This paper proposes that engaging the humanities builds an awareness and appreciation of otherness; encourages abstract (critical) thinking; fosters language development; and, perhaps most importantly, asks students to be inspired by great ideas beautifully rendered. To become a knowledge-based society, a culture of reading deeply and independently needs to be cultivated. To empower students to become lifelong learners requires that they are, by default, lifelong readers. Furthermore, I propose that in an unsettling time of growth, change and challenges in the region, there is a reassuring possibility for humanistic inclusion that transcends the standard categories of identity politics. Students in the Gulf, just as readers everywhere else in this human world, can be shown that there is more to unite us than to divide us.
\end{abstract}

\section{Introduction}

Soon we shall breathe our last. Meanwhile, while we live, while we are among human beings, let us cultivate our humanity. - Seneca

For more than twenty years, I have defined myself in relation to various academies that have functioned as primary markers of who I am: I am a student at $\mathrm{X}$ university, a teacher at $\mathrm{Y}$ university, a scholar at $\mathrm{Z}$ university. Doing so has proven to be satisfying and reassuring in that my affiliation with these institutions has served to anchor my concept of self and provided me with a community - real or imagined - to use for comparison or contrast. Being a scholar of the humanities broadly and generally construed, I recognize myself as part of an inclusive, globalized, and meta-historical intellectual discipline. In the discourse of the humanities, knowledge of history is not an end but a means to understanding, a way of individually making sense of ontology and epistemology. Said very simply, studying the Other is essential to knowing the Self, and without a life of the mind, there is only a tenuous claim for complex identity.

However, at this juncture in my career, at Zayed University in Abu Dhabi (United Arab Emirates), I find myself wondering whether I have become lost in some forgotten quarter of the barren desert since the discourse from which I have derived my identity has been repeatedly marginalized, denigrated, and alleged to be mostly irrelevant. Indeed, both at my home institution and at universities around the world, students are exposed to less and less of what I can only call sustained humanistic exposure. Not only is this a shame, but it represents a squandered opportunity to approach the goals proposed in most university mission statements. This essay, then, is a look at how the humanities matter, as they always 
have, and particularly how they can serve to advance many of the stated national priorities in emerging nations like those of the Gulf.

\section{My position}

Intellectuals from every discipline tend to privilege the academic perspectives they know best; I am no exception. I have no doubt that there are many ways to learn a nearly infinite variety of subjects. Yet when options for concentration in a particular discipline disappear entirely, as they did at ZU with the elimination of the English Literature major in 2003, I begin to worry. The students lost one of a limited number of options available to them. When the highly-touted and resource-intensive general education curriculum, called the Colloquy on Integrated Learning, slowly drifts away from primary texts and humanistic analysis, I confess to considering it a disservice to the student body. In order to pursue quantitatively measurable progress, as defined by success on standardized English language tests, we have largely eliminated the use of literary texts as prompts for writing in the three-course Composition sequence. Even the alleged Humanities course finds itself morphed into an uneasy mix of historical summaries and cobbled together fragments of original material. My own bias acknowledged, I must wonder how this gutting of the curriculum can possibly have occurred and what the consequences will be.

All of my experience, in a number of different cultures, suggests to me that the humanities matter deeply, and that a exposure to them is essential to achieving the results universities around the world are expected to achieve. Organizations like the Modern Language Association, with more than 30,000 members in 100 countries, represent a substantial number of academics, and much of the thinking behind this paper owes a debt to the newsletters, discussion boards, and publications that are the public voices of the MLA. Clearly this professional body agrees that there is something real, meaningful, and important to be found in the study of literary primary texts. When at Zayed University we eliminate the option of pursuing an English major, and then pare down the core curriculum, we are doing nothing less than denying students an opportunity to participate actively in an ancient and well-established field of intellectual inquiry.

With degrees in English, Intellectual History, and Comparative Literature, I have labored to make sense of the posts - poststructuralism, postmodernism, postcolonialism, postcapitalism, posthumanism and so forth. These complex exercises in theory have produced wide-ranging and often contentious conclusions, and they have added genuine diversity to the theoretical approaches available to scholars. Most importantly, re-imagining humanistic study, from the theoretical framework through the actual practice, has encouraged the expansion and re-consideration of both what is studied and how it is interpreted. Indeed, this evolution of critical methodologies has certainly expanded the largely myopic focus on Western intellectual history by demonstrating that entrenched thought patterns are neither universal nor ideal in a multicultural world. In my own mind, I imagine the posts not so much as revolutionary but as a natural, logical, and ongoing process of identifying flaws and synthesizing solutions. This is, after all, what the dialectical tradition is all about. The fact remains that all of these theoretical positions agree on one point: there must be an artifact to study.

My concern, however, is that at universities the world over, the teaching of theory is replacing the practice of analysis informed by theory. While providing students with various theoretical lenses through which to read an artifact is an act of empowerment, academies must be careful to retain an emphasis on teaching students to apply those theories to actual "texts" (visual, written, cultural, or otherwise). In the Gulf especially, focusing too much on theory risks further reducing the exposure to original artifacts since, generally speaking, student awareness of texts, images, and histories is 
worryingly deficient. Essentially, I am wondering how to insure that a variety of theoretical discourses can inflect and inform teaching and learning in the humanities, most particularly at the undergraduate level. My fundamental purpose is to argue vehemently for the widespread inclusion of primary texts and for a renewed focus on providing students significant practice at performing individual analysis and complex interpretation.

I propose that systematically generating enthusiastic appreciation of cultural production and acknowledging the multiplicity of interpretation strongly encourages a (lifelong) practice of reading, refines linguistic capacity, and forces individuals to conceive of themselves in relation to a broad swath of cultural and temporal Others. While humanistic learning within institutions is on the wane globally, a substantial amount of exposure happens spontaneously in highly educated societies: families provide humanistic opportunities, so do schools from primary through tertiary, as do communities at large. The intellectual infrastructure of museums, libraries, historical buildings, erudite newspapers and magazines, community theater, (quasi-)educational TV, to name several possibilities, provides potential humanistic exposure to large numbers of people. In the emerging nation-states of the Gulf, and elsewhere, such public resources are (as yet) rare or non-existent. It is thus all the more important for the schools, and later the universities, to provide an intellectual context within which students can identify themselves, and to ensure that students possess the analytical and linguistic tools necessary for the absorption and expression of complex ideas. This skill set will afford more varied opportunities for defining and developing both individual and collective identities. Ideally, a sound humanistic foundation will encourage continuous self-reflection, and empower individuals, as well as communities of whatever sort, to grow and adapt in response to the rapid changes of a globalized era.

I am fully aware that what I am suggesting may be considered dangerously provocative. My assumption that individualism is both possible and desirable in Gulf communities exposes me to harsh criticism. If Gulf society is deeply rooted in collectivism, cooperation, and collaboration, who am I to impose my conception of identity upon my students? My response is that giving students the option to decide for themselves what they want to be, and how they want to be it, is the extent of my influence. To my mind, including a solid grounding in the humanities in the core curriculum is no different from insisting that students are exposed to the fundamentals of the natural sciences: both can be provocative, and at times culturally sensitive, but I would argue that they offer important fundamental concepts that empower students to imagine various ways of understanding themselves and their worlds. I find it both fair and worthy to ask students try different subject positions, and to give them access to as many different tools for success as possible. Let us not forget that the expressly stated mission of my university calls for students to participate in the changes within the society:

Zayed University seeks to prepare Emirati students for a meaningful and successful twenty-first century personal and professional life; to graduate students who will help shape the future of the UAE; to support the economic and social advancement of the UAE; to lead innovation in...a culturally diverse, humane, technologically advanced, and increasingly global environment. (my emphasis) (Zayed University, @)

"To shape the future" in an "increasingly global environment" requires a diverse range of abilities, and to strive for "meaningful and successful...personal and professional" lives suggests that our mandate is only partly directed towards careers. If we are to prepare students to lead "social...advancement," surely we must at least encourage them to think as individuals and to question the society around them. Even on the professional front, I see great hope pinned to the concept of entrepreneurship. Innovating new solutions requires lateral thinking and someone with a good, individual, idea. My goal remains to renew our commitment to quality and to becoming an "outstanding and innovative institution," (www.zu.ac.ae/html/aboutzu.html) by offering students more ways to succeed.

Brown, C.K. (2008). Humanistic inclusion: the case for the humanities in the Gulf. Learning and teaching in higher education: Gulf perspectives 5(2). http://www.zu.ac.ae/Ithe/Ithe05_02_04_brown.htm 


\section{The development of the humanities}

The history of liberal learning and the humanities is long, complicated, and not without contention. I cannot possibly make a full accounting of this history in the present essay, but I can highlight some of the major moments, namely ancient Greece, the Renaissance, nineteenth-century Europe, and the world today. Doubtless, this is a Western history, and there may well be alternative histories of the humanities in any number of other greatly learned cultures. But the West's is the history I know, and this history informs the concept of the humanities as I am using it. That other conceptions exist is true, but for the case I am making, Western intellectual history offers a largely familiar, sustained narrative and, crucially, a reasonable diversity of accessible material. It is also noteworthy that what begins as a localized phenomenon in Athens expands steadily to the present wherein I contend that the concept of the humanities has relevance to vastly different individuals and groups. Indeed, the history of the humanities is interwoven with the history of globalization.

Perhaps by employing a word like humanities, I risk lashing my essay to an overly-determined concept. But I can neither discern nor smith a better word: nestled in the roots of the word is "human," the overarching subject-position that trumps all other identity-categories. It is the study of being human, particularly the laudable achievements of human societies, and what we all share regardless of other factors. The humanities pursue those qualities which transcend time and place, and attempt to define the most praiseworthy and damnable aspects of the species. It names the discipline which focuses on primary texts in the broadest context and which constantly reaffirms the reader/viewer/listener as integral to the meaning of the artifact. It defies objectivity in favor of a more flexible gradation of interpretation. The Presidential Forum sessions at the Modern Language Association recently sought to probe the intersections between the humanities, work, and, somewhat vaguely, the world. The organization's President, Michael Holquist (2007), wrote a working description of the humanities that bears quoting at length:

Whatever else they may be, the humanities are not the social, exact, or biological sciences. They are unique not only because they put human beings at the center of their concern. Sociology, medicine, and other disciplines outside the humanities also devote themselves to human beings. Those disciplines do so, however, by conceiving human beings as types or groups. By contrast, the humanities comprise inquires that conceive as their subject human beings who are persons, individuals. They are concerned with making sense out of lives that are theirs alone... All of us at some point in the midst of quotidian hurly-burly - at the kind of moment we call a crisis - seek answers deeper than everyday existence or mere instrumental knowledge can provide (p. 3).

Thus one of the premises upon which the discipline is based presumes the possibility, even necessity, of individualism vis a vis the collective of culture or temporality. Furthermore, regardless of whichever other identity-categories one may claim, or have imposed upon her, the meta-category of "humanity" is a trump card of inclusivity.

By casting the broadest possible net of inclusion, the humanities asks us to reflect upon ourselves in relation to a myriad of Others. I know of no better way to encourage the development of individualism than to look carefully at the profound contributions that other lone individuals have made in the history of humankind. Analyzing a text or an idea that transcends time and place forcefully argues that individuals matter and can have far-reaching influence. Furthermore, it is an easy academic exercise to convince students that they too have much in common with authors and their characters, artists and their subjects, and philosophers and their conceptions of the mind. For a developing nation-state like the UAE, and of course for a developing student mind, such notions at once provoke and reassure. When placed into a broader context, my hope is that the latter wins the day: how profoundly helpful must it be to realize that many generations of individuals have felt similar emotions and risen to

Brown, C.K. (2008). Humanistic inclusion: the case for the humanities in the Gulf. Learning and teaching in higher education: Gulf perspectives 5(2). http://www.zu.ac.ae/Ithe/Ithe05_02_04_brown.htm 
overcome similar challenges. In the end, the study of the humanities is much about taking that which is timelessly great, dusting it off, and placing it into one's own personal and private collection of influences. Human cultural production is akin to an effectively unlimited and egalitarian bank account: anyone with the requisite language skills, and a bit of analytical coaching, can make withdrawals as and when needed. It is the rich legacy bequeathed to all of us all, and educational establishments have the duty to teach students how to use their assets.

Since the ancient Greeks, Western intellectual tradition has valued the connections between education, learning, and thinking individually. Already in the fourth century BCE, Socrates knew that the choices made in a curriculum mattered greatly: students will always be impressionable, and "any impression we choose to make leaves a permanent mark" (my italics) (Dorsch, 1965, p. 11). For Socrates, education was not a rigidly delineated span of time in one's life; rather it was a lifelong endeavor. The wisdom of Socrates derived from his certainty that he always had more to learn. While learning in the ancient world was a far cry from modern educational assembly lines, Golden Age Greece is generally accepted as the source of the basic concepts that shape the humanities today. As Martha Nussbaum (1997) has noted, Socrates granted humanists some of their dearest values: constant and critical self-evaluation, an idealized notion of the world citizen, and the concept of imagination as a narrative. The speculative leap of philosophy, the psychological intimacy of drama, and the individualized idealism of the sculpture embody these virtues and remain important examples to be studied. Herodotus, with his attempts at capturing history from various perspectives, or Sophocles' character Antigone, who makes a radical decision that individuates her from her sister Ismene, supports the notion of ancient Greece as constituting a formative humanistic era. The Greek concept of paideia, generally denoting education in the liberal arts, was thought to be that which separated civilized humans from barbarians. The identity politics of Ancient Greece insisted on broad humanistic learning as the defining characteristic of civilization. It was left to Alexander to convey the concepts and methods widely, and violently, across Asia. While much criticism of Alexander can be made, his conquests proved to be a lucky chance of history in one regard: Hellenistic expansion provided multiple back-up sites for the classical learning of the Greeks.

The humanities in Europe arose anew in the Renaissance, and served foremost to distinguish different classes of people via a complex set of relationships. As with the Greek paideia, the Latinified concept of liberal learning focused on retained the Greek delineation between homo humanus and homo barbarus. Both share the biological homo, but split the species into humane and barbaric variants. The Renaissance conception, however, added a third term to the equation, the difference between human and divine (Ghilders and Hentzi, 1995, p. 140). In other words, the binary relationship from the Greeks became tripartite: barbarians on one side, God on the other, civilized man in between. The liberal arts thus became that which defined humankind and fostered virtue in the human realm. It remains an easy leap to Burckhardt's thesis that it was only in the Renaissance that the individual was invented (1958). These free individuals, squeezed between the divine and the uncivilized, looked to the humanities to guide them in their new intellectual freedom. In so doing, the humanities, "celebrated the specificity of human knowledge and certain practices of learning in contrast to those of presumably benighted opponents associated with faith, revelation, and dogma. Humanism elevated the truth of textual study against the obscurantism of power" (Berman, 2007, p. 211). There can be little doubt that this process is simultaneously liberating and potentially revolutionary, then as well as now.

Not coincidentally, the era of European colonialism and the formation of modern nation states was also the period when the university took its modern form. Once again, the humanities were at the core of the endeavor, and pursuit of the classics and the liberal arts was initially the majority of what universities offered. During this period the humanities began to question the established social, 
religious, political, and artistic status quo; the discipline was respected alongside the emerging hard sciences as a powerful tool for making sense of a turbulent and changing world. The nineteenth century also attached the adjective "secular" to humanism to suggest the fading influence of religion in Europe. In some quarters, the humanities have subsequently been tainted so that all humanism appears to be intractably secular. In pure point of fact, this need not be the case, yet in the minds of fundamentalists the world over, humanism offers a ready target because it includes that which is manifestly hostile to religion in principle. This may explain an element of resistance to the liberal arts in the modern Middle East, but I do not believe that religious faith and humanistic learning are necessarily adversarial. Just as with science courses that present culturally or religiously problematic options, study of the humanities must be guided with care and respect for local sensitivities.

Through the early twentieth century, the humanities played an important role in the academy, and retained a certain amount of respect within Western culture at large. But reforms in all aspects of thinking, teaching, and learning have taken a mighty toll on the credibility of the discipline. Most prominently, the so-called culture wars have hammered the humanities and even asserted, from some positions, that the discipline is a major part of the problem. While I agree that there is always room for improvement and reform - and for new texts, perspectives, and methodologies - the fundamental impulse of the liberal arts remains sound, worthy, and full of promise. Perhaps by adopting a critical distance and learning from this ideological struggle (dare I say, kulturkampf), I suggest that instead of sounding the death knell of the humanities, the acrimonious debates of the last few decades confirm nothing more than the notion we began with in Socrates: that texts matter, and that reading widely leaves an impression on students. Rather than throwing out the discipline because it cannot agree on methodological or even philosophical questions, I contend that the culture wars broadly indicate a need for more, not less, humanistic education in academies.

The story of the culture wars is hideously complex in terms of details, but reasonably straightforward in summary; let me attempt a thumbnail sketch of the latter. Whereas the traditionalists posited a canon and argued for a return to classical-based humanism, the reformists sought to create a much broader collection of texts and a wider range of methodological possibilities to access them (Watson, 2002). This debate was not radically new, but it was played with such zeal and personal rancor that it caught the attention of large numbers of academics and pundits, and subsequently it became an embarrassing cause célèbre that generated an enormous number of books, articles, and conferences. As the debate quickly assumed the stature of full-blown war, the focus shifted from the canon to the university itself, and particularly how the curriculum was taught. Universities throughout the U.S. stepped up their curricular reform movements, and the squabbling programs found themselves under serious administrative scrutiny. Skirmishes continue to flare up, particularly around theoretical issues and methodologies.

Traditional humanism served as a lightning rod for critique by the reformist camps. Humanism contends, generally, that freedom of thought and action are hallmarks of individuals; postructuralists retort that such freedoms are in fact constrained by linguistic, psychological, or socioeconomic conditions (Ghilders and Hentzi, 1995, p. 141). Traditional humanists contend that individual agency is a universal attribute, whereas many postcolonial critics insist that this agency is bounded by race, class, gender, or sexual orientation. The argument proceeds to suggest that positing universal human traits is oppressive, essentialistic, and exclusionary. Instead, the posts argue, discourse or ideology are the taskmasters. That may indeed be so, but in this climate of bellicosity, the American academies may well have alienated their core constituencies: undergraduate students and their families, potential employers of graduates, and intellectuals at large. Perhaps one of the reasons this struggle spread so widely is that everyone has equal access to the texts that make up the focus of humanistic study. Few laymen would

Brown, C.K. (2008). Humanistic inclusion: the case for the humanities in the Gulf. Learning and teaching in higher education: Gulf perspectives 5(2). http://www.zu.ac.ae/Ithe/Ithe05_02_04_brown.htm 
dare launch into an academic dispute over particle physics or even Hegelian dialectics because the public, mostly, has very limited access to the material. But once the debates shift into the realm of favorite books or paintings, everyone feels part of the discussion. Thus the liberal arts found itself with a collective black eye.

My concern is not so much to take sides as to note that the vehemence of the debate argues powerfully for the fact that the humanities still matter, regardless of the precise choice of texts or the methodology used to interpret them. In a peacemaking gesture, Marjorie Garber (1991) tried to rise above the fray by arguing in Academic Instincts that the bitter debates are the whole point of intellectual life. It is such passionate disagreement that keeps intellectualism from vanishing entirely in a multimedia-saturated world. Such a move seeks to re-focus scholarly energies and perhaps to remind the academic community of the tenets of civility. As Socrates noted long ago, dialogue requires a willingness to hear the adversary fully and fairly. It is the job of the humanist to listen, to contextualize, and to make sense of ideas. We make a grave mistake by presuming that somehow the contemporary era is divorced from the past: it is not. By isolating ourselves in intellectual cocoons, or worse yet, hives of like-minded wasps, we provide miserable examples for our student. Rather, debate and openness to difference need always be at the core of the humanities. After all, "[t]he work of the humanities is... a complex act of remembering and witnessing to provide materials that are useful in creating links between my 'hereness' and the world's 'there-ness'" (Holquist, 2007, p. 3). What individual instructors choose to recall from history, and import into the fresh minds of their students, will always be contentious. But if the object of the exercise is to encourage unique, free-thinking, individuals, there must be many possible avenues. Studies in the liberal arts thus remain essential to the process of reflection and to identity recognition (to say nothing of identity formation).

\section{Benefits of the Humanities for the Gulf Region}

The point I am driving towards is that in societies like those in the Gulf, where educational institutions and the role they play are only beginning to coalesce, what types of courses are offered matters much more than what books or methodologies are used in those courses. The objective is to coax students to reflect, not to gather a randomized sample of diversity or comfortably constructed examples that confirm what they already know. Sustained engagement with entire texts, artifacts, and ideas, not as bit players but as things unto themselves, needs to figure prominently in courses offered at both high school and university levels. Unfortunately, at present in the UAE, the commitment to the humanities is minimal and perhaps misguided. Primary texts are vanishing, and quality - of thinking, of writing, of influence on subsequent texts - seems to be of secondary consideration. Across the region, even in societies that appear to have a more developed sense of educational refinement and traditions of intellectualism, the humanities are on the wane (Komis and Nicholls, 2000). Nonetheless, even a cursory glance at institutional mission statements and learning outcomes suggests close alignment with the goals that have always been at the core of the discipline. Why then are we collectively shying away from engagement with this field of study?

Perhaps an obvious response comes from the impulse to produce students who are ready to take up jobs after graduation. Traditionally, the role of the university has been mostly to retain the social status quo. In Europe as in Asia, academies have served

to create, distribute, and conserve knowledge,... [and] to reproduce status hierarchies by credentializing students... In modern societies, research and credentialization have become both more crucial and more pervasive, even determining the fate of nations. Research is the basis for economic, political, and military power, while professionalization makes universities the gatekeepers for most positions of comfort and status (Delany, 2000, pp. 89-90).

Brown, C.K. (2008). Humanistic inclusion: the case for the humanities in the Gulf. Learning and teaching in higher education: Gulf perspectives 5(2). http://www.zu.ac.ae/Ithe/Ithe05_02_04_brown.htm 
No one can seriously assert that literature graduates should ply their trade in the poetry factory, or that philosophy students are being prepared to labor in the idea mines, but placement data from across the world suggests that liberal arts graduates are not only hirable but often desirable. Professional certification and training certainly do build skill-sets, but I am not convinced that this is the right option for all students. From my liberal perspective, a vocation is as much about sustained development of one's professional identity and the continuation of learning - about oneself, about the world, about the job. By doggedly seeking to give students access to the obvious job opportunities, perhaps we have failed to give them examples of and practice with making sense of their role the human world. If we are being honest about preparing students for careers, not jobs, we need to give them more of the tools to construct, if they choose to, a unique and individual path for their lives. Furthermore, if part of our mission is to prepare students for meaningful personal lives, how do we best achieve that goal?

One of the most urgent educational needs in the region is to move beyond the rote acquisition of basic facts towards a more nuanced exposure to powerful, marvelously rendered primary texts. The ancient Greeks make great sense to my students. They find Socrates and Antigone and Priam displaying emotions that are mostly familiar. Mughal miniature painting, with its vibrant colors and painstaking detail, and Mafouz's complicated human networks both capture their imagination. Persian architecture - Islamic but different - or the borrowing of Arabic courtly styles in Troubadour lyrics suggest to students a huge array of different connections between histories. Nineteenth-century novels also work wonderfully: students can relate easily to Jane Eyre's yearning for love and respect, Nicholas Nickleby's dogged perseverance and concern for his sister's honor, and Victor Frankenstein's mania for achievement. My point is not to produce a canon of "texts" but to suggest that students gain so much from closely reading, analyzing, discussing, and writing about these sorts of primary artifacts. They relate to these stories, and they empathize. When such texts are woven into the context of history, students quickly recognize that neither cultures nor individuals exist in a vacuum, and that the fundamental human questions have remained much the same over the centuries. This, to me, is a far richer result than usually included under the heading of "global awareness." Love, death, deception, evil, beauty, or dozens of others, are the humanistic themes that can provoke human understanding of other cultures. To my mind, tracing these themes strongly supports the quest for awareness of, and respect for, cultures that may be different racially, religiously, or ideologically.

"Critical thinking" is a bugbear at educational institutions the world over. Indubitably, it is a worthy goal, but also it is an outcome that is notoriously difficult to define and assess. My own comprehension of this complex term entails observing phenomena from different perspectives, abstracting elements of the subject and judging them logically and critically, and then expressing those patterns of thought in clear and precise language. A tall order indeed, but precisely what students of the humanities have been asked to do for millennia. Thinking critically about art, literature, and ideas is part and parcel of understanding them; teaching humanistic texts is all about perspective, judgment, and expression. Michael Riffaterre (1995) argues that what makes a text "literary" (or, I might add, humanistic) is its having been decontextualized from its original circumstances. Classroom instruction, he continues, buoys artifacts so that they "survive the extinction of the issues, the vanishing of the causes, and the memory of the circumstances to which that text responded" (p. 70). By way of an example, I cite my experience in the Zayed University Humanities course (COL 155). When I ask students if they imagine themselves more like Antigone or her sister Ismene, they are forced to re-contextualize Antigone's resistance to patriarchal authority into their own world. While most wish to be brave, honor-driven, and loyal to religious law over royal edict, they are also honest about how difficult that would be given that a death sentence is the likely result. They have taken a scene from a story, abstracted a course of action, evaluated it, and then applied it to the world they live in. In so doing, they gain insight into the text - 
and the culture that produced it - and they build links from the ancient past to the immediate present. Clearly, this result is successful as an example of critical thinking, and it is assessable. Sadly, Antigone is often the only complete primary text they read in the course, and the course itself is the only overt humanities course in the core curriculum. One instance is not nearly enough to fix the pattern and process in their minds.

Language proficiency remains doubly emphasized in many mission statements: it is an assessable thing unto itself, but also essential for comprehension of texts and course material in every discipline. As a function of history and contemporary geopolitics, English is the language of choice in the Gulf. How then to build English capacity to such a level that complex thoughts are captured - if not thought originally - in that language? Language is subtle and slippery, and only diverse experiences with different tones, styles, and techniques can teach students how to interpret logically and critically. One of my favorite classroom exercises over the years, both in the UAE and the US, is to assign students to read Jonathan Swift's "A Modest Proposal". Always a few, sometimes a crowd, respond with indignation: "Sir, he is an evil man, he is proposing eating babies!" they shriek. These students are in good company: when initially published in 1729 , the public outcry was shrill. Only by looking closely at the tone and the context of the essay can I begin to demonstrate the nature of Swift's satire. Literally, and logically, his case is sound, but his proposal is ridiculous. He inspires an emotional response because his argument resists direct and logical refutation. It is only by abstracting the ideas and reading the argument analogously that we begin to see the subtlety of his language, and then we recognize his game. The results of the lesson are many: students see very clearly that arguments are not always what they seem to be, and they learn that language can be deceptively tricky. Perhaps most importantly, they remember the lesson - at least through the term - and are forevermore looking to avoid being duped by satire. It is this sort of success with humanistic texts that provides lessons in language and critical thinking.

Language in the Middle East is always a sticky subject. With English, perhaps grudgingly, accepted as the lingua franca, there is an understandable resistance to the subtle forms of language play that define literature and poetics. It is hard enough for native speakers permanently immersed in English to make the language their own by acquiring a unique voice and the ability to connote deliberately. But the stakes are too high to aim for a communicative mediocrity. Words are good things to think with, and language is a form of power. The modern era is littered with examples of words as highly influential in the development of revolt and rebellion. Revolutions begin in language and radiate outwards into action, but as the history of propaganda will attest, adopting words or phrases carelessly can make one an unwitting participant. Writing on the topic in Lebanon, Ken Seigneurie (2000) notes that

... language becomes merely instrumental at best, meaningless smoke and mirrors at worst. In the instrumental phase, little play is perceived between signifier and signified - the kind of play that the allusiveness of literature demands - and language appears rigid, devoid of irony, laden with certitude. In the smoke-and-mirrors phase, language means anything or nothing for the nonce, an utter breakdown of semiosis. In either case, the mental suppleness needed to seriously maintain two ideas in balance with one word vanished; opinions become either ideological fortresses or opportunism's playthings. In such an environment, the intellectual rigor needed to link ideas with consistency atrophies, and with it goes rational argument (p. 52).

Closer to home in the UAE, I share his concerns. Sadly, at all levels of the community, English usage is sloppy, and often leads to miscommunication and misunderstanding. Imprecise language usage may result from insufficient skills, but it may also belie an unmindful attitude towards the power of language and the important concepts represented by words. At worst, casual language usage is a symptom of careless thinking. In my courses, it is a revelation to some of my students that they are saying 
something completely different than they mean. By holding them to account for their choices of words and the logical causal structures implied by their grammar, they begin to see that semantics and syntax are crucial to the delivery of meaning. I know of no better way to demonstrate this to students than by giving them well-crafted, subtle, and powerful texts to read, analyze, and discuss. Doing so reinforces the concept that language is polysemous and that many seemingly simple sentences are open to interpretation.

Explicit in the mission of my university is the desire to build productive members of society. Welleducated, articulate, and analytical citizens are essential to the continued, and remarkable, development of the region. The stakes are high and the opportunities are grand, but building a nation is far more than paying for physical construction and delegating labor. Forming a nation requires both consensus and dissent, and a willingness to seek remedies for social, cultural, intellectual and other deficiencies. The history of the UAE as a unified country has been brief but illustrious, yet too little sustained work has been done to conceive of and articulate the variety of ways citizens can contribute to the nation. There is much work to be done, both in theory and in practice, to discover the limits of acceptable individualism. The educational system must encourage, perhaps even insist, that students individually figure out for themselves who they are and who they want to be. Only then can they begin to imagine the full range of options to participate in building the nation. To know one's own national history is not enough; there must also be critical reflection informed by global awareness. Perhaps the most concise description of this process comes from the British historian Catherine Hall (2002). Describing her own path of revisionism, she contends that "in order to understand the specificity of the national formation, we have to look outside it. A focus on national histories as constructed, rather than given, on the imagined community of the nation as created, rather than simply there, on national identities as brought into being through particular discursive work, requires transnational thinking" ( $p$. 9). Precise thinking, reflection, careful revision, and the dissemination of clearly rendered ideas are the building blocks of individual and national identities. These skills are not coincidentally what the humanities are ideally suited to develop.

In her spirited defense of the humanities, Martha Nussbaum (2000) explains that a liberal arts education is the only way to "develop each person's capacity to be fully human, ... self-aware, self-governing, and capable of recognizing and respecting the humanity of all our fellow human beings, no matter where they are born, no matter what social class they inhabit, no matter what their gender or ethnic origin" ( $p$. xiii). This is what students the world over need, perhaps more than anything else. Teaching young people to appreciate the solitary and rewarding pursuit of reading is the first step towards creating lifelong readers and learners. What people choose to read, over a lifetime, is a personal decision, but while the opportunity remains at schools and universities to guide their choices and to cultivate their ability to read broadly and deeply, it seems remiss to shy away from the highest standards. Strongly encouraging students to think about the big humanistic questions necessarily causes them to reflect upon themselves. Coaching them to argue logically and persuasively using evidence instills a habit of mind that contributes to social values like fairness, justice, and tolerance. Insisting that they use language carefully and accurately hones the sharpness of their thinking. To attain these goals, it is my firm belief that the humanities must be strengthened and sustained more fully and consistently in the $\mathrm{UAE}$, in the region, and in the world. To do so serves to compliment other majors, like Communications or the Social Sciences, that seem to be more in fashion at the moment, and to amplify some of the skills that that these disciplines also produce.

Over the millennia, humankind has bequeathed to the present era a vast and ever-expanding collection of artistic jewels to be gathered up at will. Which diamonds are examined at the university is a moot point: any of genuine quality and timelessness will do. The important thing is to inspire students to seek

Brown, C.K. (2008). Humanistic inclusion: the case for the humanities in the Gulf. Learning and teaching in higher education: Gulf perspectives 5(2). http://www.zu.ac.ae/Ithe/Ithe05_02_04_brown.htm 
these texts and to make their own meaning from them. There is a magic to the humanities that is desperately needed in the contemporary world: across vast spans of time and place, voices speak to us. As Calvino (1999) notes, a great text "is a work which relegates the noise of the present to a background hum... [but] which [also] persists as background noise even when a present that is totally incompatible with it holds sway" (p. 8). In order to cultivate future generations of respectful, open-minded, and inquisitive humans, the humanities offer a pathway. Opening minds to possibilities simultaneously opens the door to opportunities. As the relentless pace of change continues - here in the UAE and elsewhere - young people need to be equipped with skills to reinvent themselves repeatedly. If "[i]dentity is conjunctural, not essential," (Clifford, 1998, p. 11) we in the academy must tirelessly find ways to conjure up models for our students to emulate, and continually cause them to reflect upon that most fundamental of all humanistic questions: who am I?

\section{References}

Berman, R. (2007). The Humanities, Globalization, and the Transformation of the University. Profession, 2007, 211-217. New York: Modern Language Association.

Burkhardt, J. (1958). The Civilization of the Renaissance in Italy. New York: Harper \& Row.

Calvino, I. (1999). Why Read the Classics? New York: Pantheon Books.

Clifford, J. (1988). The Predicament of Culture. Cambridge, MA: Harvard University Press.

Delany, P. (2000). The University in Pieces: Bill Readings and the Fate of the Humanities. Profession, 2000, 89-96. New York: Modern Language Association.

Dorsch, T.S. (Ed. and trans). (1965). Classical Literary Criticism. New York: Penguin.

Garber, M. (1991). Academic Instincts. Princeton, NJ: Princeton University Press.

Ghilders, J. \& Hentzi, G. (Eds., 1995). The Columbia Dictionary of Modern Literary and Cultural Criticism. New York: Columbia University Press.

Hall, C. (2002). Civilising Subjects. Cambridge: Polity Press.

Holquist, M. (2007). The Humanities at Work in the World. MLA Newsletter, Winter 2007.

Komins, B. and Nicholls, D. G. (2000). The Humanities Abroad. Profession, 2000. New York: Modern Language Association.

Nussbaum, M. (1997). Cultivating Humanity: A Classical Defense of Reform in Liberal Education. Cambridge, MA: Harvard University Press.

Nussbaum, M. (2000). Forward. In M. Nelson (Ed.) Alive at the Core: Exemplary approaches to general education in the humanities. San Francisco: Jossey-Bass.

Riffaterre, M. (1995). On the Complementarity of Comparative Literature and Cultural Studies. In Bernheimer, C. (ed.), Comparative Literature in the Age of Multiculturalism. Baltimore: Johns Hopkins University Press.

Seigneurie, K. (2000). The Flickering Light of Literature: 8-18 February 2000. Profession, 2000. New York: Modern Language Association.

Watson, P. (2002). The Modern Mind: An Intellectual History of the 20th Century. New York: HarperCollins. 
Zayed University (n.d.). About Zayed University. Accessed 4 June 2008 at www.zu.ac.ae/html/aboutzu.html

\section{Author}

Christopher K. Brown, Associate Professor of English Language \& Literature, Zayed University, Abu Dhabi 